\title{
An abrupt change in winds that may radically affect the coasts and deep sections of the Baltic Sea
}

\author{
Tarmo Soomere $^{1,2, *}$, Steven R. Bishop ${ }^{3}$, Maija Viška ${ }^{1}$, Andrus Räämet ${ }^{1}$ \\ ${ }^{1}$ Institute of Cybernetics at Tallinn University of Technology, Akadeemia tee 21, 12618 Tallinn, Estonia \\ ${ }^{2}$ Estonian Academy of Sciences, Kohtu 6, 10130 Tallinn, Estonia \\ ${ }^{3}$ University College London, Gower Street, London WC1E 6BT, UK
}

\begin{abstract}
We explore long-term variations in the properties of waves in the Baltic Sea and geostrophic air-flow over this water body. Records of visual wave observations from 1946 to 2012 at 8 observation sites at the eastern coast of the Baltic Sea reveal a multitude of changes. A substantial decrease in the wave heights took place until about 1970, and considerable decadal variations have occurred since then. The coherence between annual average wave heights at different locations was lost at the end of the 1980s. A rotation of the usual wave approach direction by almost $90^{\circ}$ was identified at one location. We then coupled this data with a reconstruction of wave fields and wave-driven sediment transport for 1970 to 2007. The reconstruction is based on adjusted geostrophic winds from the Swedish Meteorological and Hydrological Institute. The simulated net potential sediment transport along the eastern coast of the sea reveals a major change at the end of the 1980s. This change is associated with an abrupt turn of the geostrophic air-flow over the southern Baltic Sea by $\sim 40^{\circ}$ around 1987 . This change may serve as an alternative explanation for a radical decrease in the frequency of major inflows of saltier, oxygen-rich water into the Baltic Sea since the mid-1980s.
\end{abstract}

KEY WORDS: Wave climate - Wave observations - Wave direction - Baltic Sea $\cdot$ Sediment transport $\cdot$ Regime shift $\cdot$ Geostrophic air-flow

\section{INTRODUCTION}

The Baltic Sea is the Earth's largest brackish water body and one of the top 10 most threatened waters (Uggla 2007), with a unique, yet sensitive marine environment. It is not only under extensive anthropogenic pressure (by e.g. extremely busy shipping, large industrial regions, eutrophication and acidification; Backer et al. 2010) but also particularly vulnerable to potential changes in climate (BACC 2008). The key factor is that the Baltic Sea has a limited water exchange with the open ocean. The sea is strongly stratified, and oxygen primarily reaches its bottom waters via major salt water inflows (major Baltic inflows, MBIs) from the North Sea. These inflows have stopped almost completely in recent years (BACC 2008, Nausch et al. 2013), while at the same time,

${ }^{*}$ Corresponding author: soomere@cs.ioc.ee shift-like changes in water temperatures (Mohrholz et al. 2006) and stratification (Väli et al. 2013) have occurred. Because any variation to the MBIs may drastically impact the entire ecosystem, there have been recent debates for and against calls to engineer ways to oxygenate the sea (Conley 2012), which has also widened the political debate (Elmgren et al. 2012).

Here, we collate data from the recent research into the Baltic Sea wave climatology and abrupt changes to the drivers of its wave climate. Among a variety of indicators of climate change, properties of surface waves serve as a naturally integrated measure of the driving forces of seas and oceans, and especially of their changes (Hemer et al. 2013a). We explore longterm variations in wave properties in the Baltic Sea based on observed time series from 1946 to 2012 and a reconstruction of wave fields and wave-driven sed-

() The authors 2015. Open Access under Creative Commons by Attribution Licence. Use, distribution and reproduction are unrestricted. Authors and original publication must be credited. 
iment transport for 1970 to 2007. The analysis reveals several major changes in both wave properties and wave-driven processes from the end of the 1980s. The changes can be associated with an abrupt turn of the geostrophic air-flow over the southern Baltic Sea since 1987 . This turn may serve as an alternative explanation for the almost complete vanishing of MBIs since the mid-1980s.

\section{DECADAL CHANGES IN OBSERVED WAVE HEIGHTS AND DIRECTIONS}

While most previous research into marine climate changes has focused on variations in the hydrographic properties (such as water temperature/heat content [Rosenthal et al. 2013] or salinity [Durack et al. 2012]), plus changes in the scalar properties of their drivers (Weisse \& von Storch 2010) (such as the wind speed), in shelf and semi-enclosed seas, many dynamical features (circulation patterns, pollution transport, coastal flooding) are strongly determined by wind direction. The related changes to the wave properties (Hemer et al. 2013a) and the level of exposure of the nearshore area to the hydrodynamic loads may have substantial consequences for safety issues and also on coastal processes and nearshore ecosystems.

Wave simulations are useful to identify such changes, but at times, they reveal highly controversial results depending on the particular wind reconstruction (Young et al. 2011, Wentz \& Ricciardulli 2011, Bertin et al. 2013, Hemer et al. 2013a). Wave records and analyses of wave-driven coastal processes often provide a better option to reveal, visualise and quantify these changes. While in the open ocean the rotation of the wave climate is usually confined to a few degrees (Hemer et al. 2013b, Idier et al. 2013), for regions that are sheltered from remote swells, these changes are more locally driven and can be much greater (Soomere \& Räämet 2011).

The array of wave data used for identification of changes in sea conditions should have a spatial resolution that is fine enough and temporal coverage that is long enough to represent these changes. This requirement is usually not satisfied because instrumented wave measurements extend back no more than a few decades. An exception is the Baltic Sea, where regular visual wave observations have been performed since 1877 (Rosenhagen \& Tinz 2013). Because south-western winds predominate in this basin, the most valuable data stem from the hydrometeorological stations of the former USSR. These sta- tions are located along the eastern coast of the sea (Fig. 1) and have used the same procedure for measurement since 1946. The number of single observations varies from 13000 (Pakri, 1954-1985) up to 60 000 at Liepaja and Ventspils (Soomere \& Räämet 2011, Soomere 2013, Zaitseva-Pärnaste 2013).

Despite suffering from some quality issues (Gulev et al. 2003), large sets of visual wave observations provide consistent information about changes in the wave fields (Gulev \& Grigorieva 2004). It is still not clear a priori which visually observed wave properties can be trusted (Zaitseva-Pärnaste 2013). The applicability of the outcome of visual observations for the identification of changes in the wave field can be highlighted by considering the average wave heights for single calendar days (Fig. 2). The resulting variations on weekly scales usually fade out when the averaging time interval is increased and may be completely different for different time intervals (Soomere et al. 2012). The observed weeklyscale variations are highly coherent along the entire eastern Baltic Sea coast (e.g. the correlation coeffi-

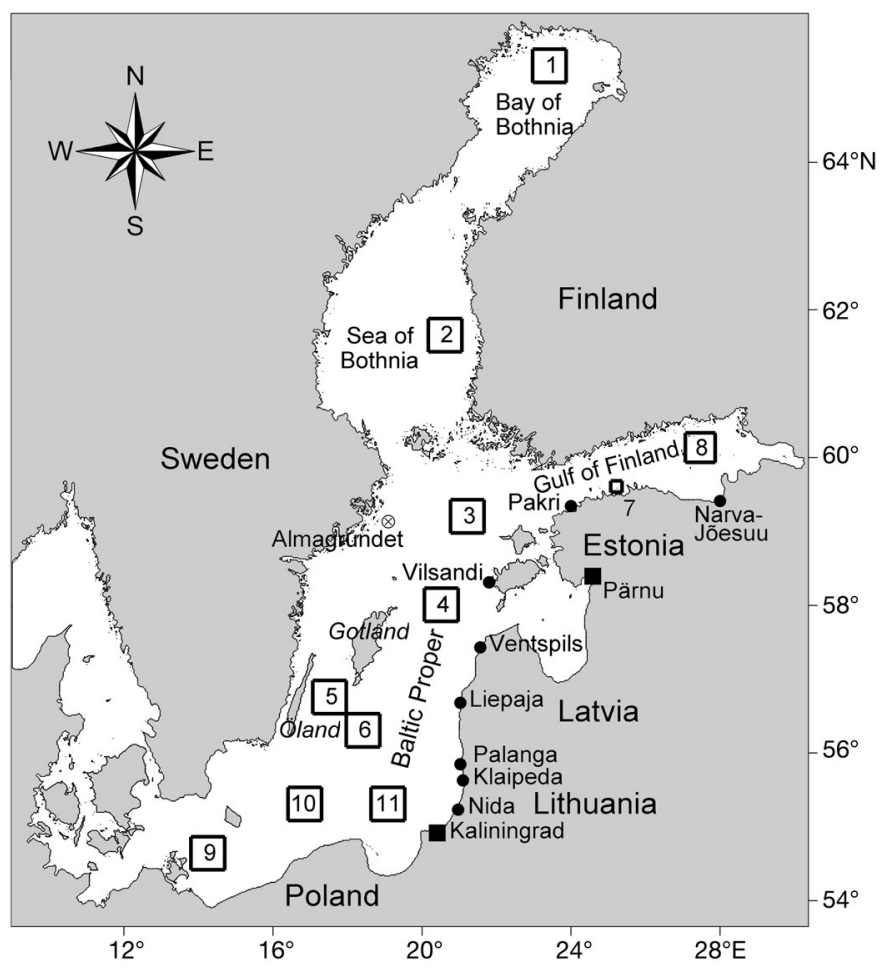

Fig. 1. Location scheme of the Baltic Sea showing Areas $1-11$, for which the average geostrophic air flow is presented in Figs. 5 \& 6; visual wave-observation sites $(\bullet)$ at the eastern coast: see Figs. 2 \& 3; instrumental wave-measurement location at Almagrundet; boundaries of the study area (ם) for alongshore sediment transport: see Fig. 4 . The relatively small Area 7 is located near the southern coast of the Gulf of Finland 


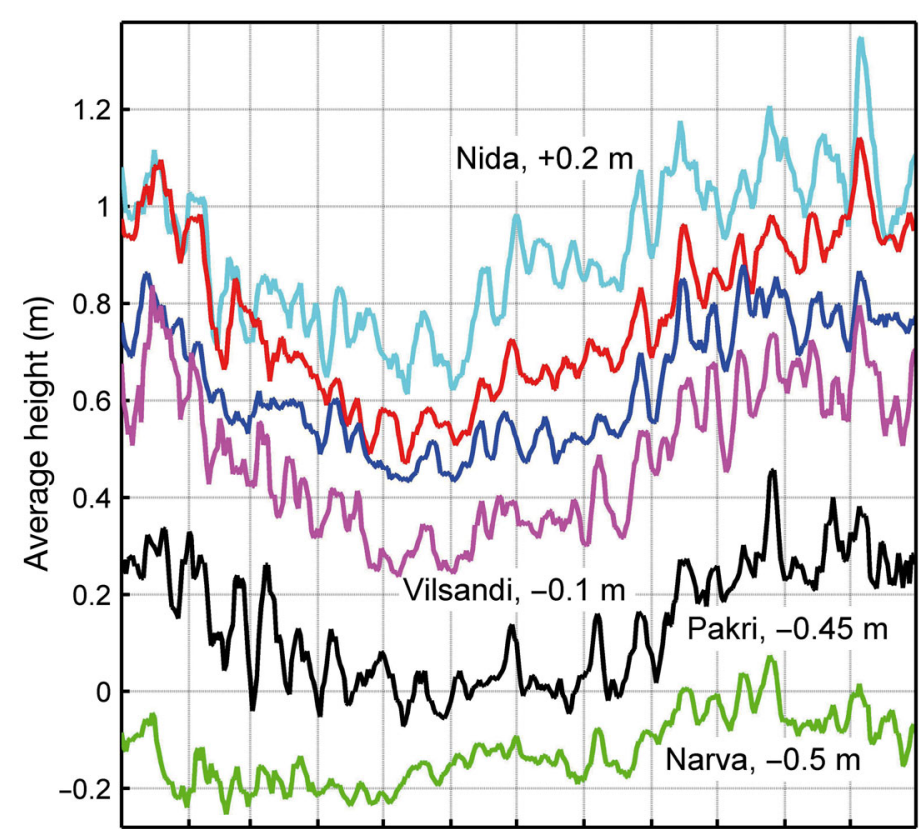

Jan Feb Mar Apr May Jun Jul Aug Sep Oct Nov Dec

Fig. 2. Variation of the average mean wave height ( $5 \mathrm{~d}$ running average) for single calendar days at selected stations. Red: Liepaja, blue: Ventspils (both 1954-2011). Data for other stations (Nida 1954-2009, Vilsandi 1954-2008, Pakri 1954-1985, Narva 1954-2008) are shifted vertically for better visibility

cient $\mathrm{r}=0.87, \mathrm{p}<0.0001$ for Ventspils and Liepaja; Soomere 2013). This coherence signals that, notwithstanding a low accuracy of single recordings, visually observed data sets consistently (albeit not always perfectly) reflect changes in the wave properties.
The observed annual mean wave heights reveal marked decadal patterns (Fig. 3). Differently from many reconstructions of the course of wave heights, e.g. in the northern Atlantic (Semedo et al. 2011), the wave intensity gradually decreases from the mid1940s until about 1970 along the entire eastern Baltic Sea coast. Although the magnitude of this decrease (by almost a factor of 2) may be somewhat overestimated, it is very likely that the presented data mirror a major change in storminess (Alexandersson et al. 2000) and the Baltic Sea wave fields during the 20th century. These changes resemble the well-known 'hockey-stick' curve of recent changes in climate in a reversed manner: instead of a large increase at the end of the century, a major decrease in the average wave height apparently occurred, at least in some parts of the Baltic Sea, in the 1950s to 1960s.

Although there is effectively no change in the numerically simulated average wave height for the entire Baltic Sea (Soomere \& Räämet 2014), local variations in the wave height are considerable on decadal scales, as noted by Soomere \& Räämet (2011) based on fewer observation sites. The variations in the observed wave heights are markedly synchronous in counter-phase for the southern and northern parts of the Baltic Sea since the 1970s. They culminate in the 1990s, when the majority of wave energy was concentrated in the northern Baltic Proper between Almagrundet (Broman et al. 2006) and Vilsandi (Fig. 1). This maximum in the long-term course of wave height occurs synchronously with an extremely large number of days per annum with low pressure in Härnösand, Sweden, a phenomenon that

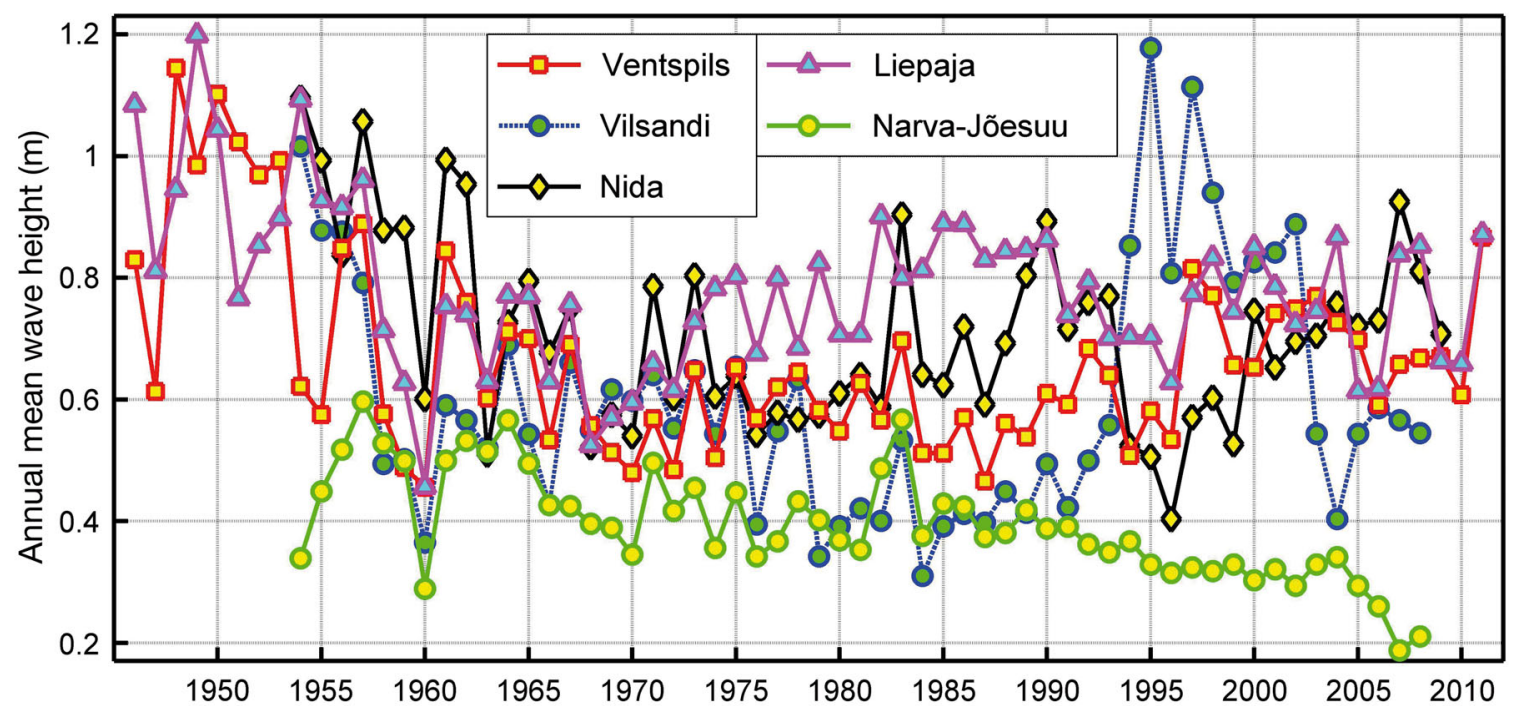

Fig. 3. Annual mean wave height at 5 observation sites on the eastern Baltic Sea coast. Wave heights for Ventspils and Liepaja for 1946-1953 are from Soomere (2013) 
seems to take place once or twice a century and that happened in the 1990s (Bärring \& von Storch 2004). This phenomenon matches the overall tendency between 1948 and 2000 for the trajectories of cyclones reaching Northern Europe to move northward (Sepp et al. 2005). These 2 features can be interpreted (albeit somewhat speculatively) as reflecting a process during which the storm cyclones predominantly cross the Baltic Sea at latitudes of about 62 to $63^{\circ}$ N. During such events, strong winds are concentrated in the northern Baltic Proper, and much less wavegenerating forcing remains in the southern Baltic Sea.

\section{A SHIFT IN WAVE PROPERTIES AND COASTAL PROCESSES IN THE 1980s}

The interannual variations in the observed wave heights are highly correlated and in-phase for the entire eastern coast of the Baltic Proper (Fig. 3). Until 1987, this property was also true in the Gulf of Finland (Fig. 1). Since 1988, however, the interannual variations at Narva-Jõesuu are completely out of phase with those along the open Baltic Sea coast. Thus, while storms before 1988 have created high waves more or less simultaneously in the entire sea, since then, periods that have led to wave storms in the Baltic Proper correspond to relatively calm periods in the Gulf of Finland and vice versa. This change has been accompanied by pronounced changes in the predominant wave direction at Narva-Jõesuu (where the most frequent approach direction of waves has turned by $>90^{\circ}$; Räämet et al. 2010) and is mirrored by a gradual increase in the frequency of southwestern winds in this region (Jaagus \& Kull 2011).

Further evidence of changes can be extracted from an analysis of the net and bulk wave-driven potential sediment transport along the sedimentary part of the eastern Baltic Sea coast. The analysis was based on the nearshore wave properties reconstructed using the third-generation spectral wave model WAM. It was run with a spatial resolution of 3 nautical miles for the entire Baltic Sea for 38 yr (1970 to 2007) in idealized ice-free conditions (Soomere \& Räämet 2011). Ignoring ice makes it possible to separate purely wind-driven (albeit not perfectly realistic) changes to the wave fields and wave-driven phenomena. The model was driven by adjusted geostrophic winds from the Swedish Meteorological and Hydrological Institute's database. This information is available since 1970 with a time step of $6 \mathrm{~h}$, and since 1977 with a time step of $3 \mathrm{~h}$. These data are calculated from the spatial air pressure distribution, and thus represent global (on the scale of the Baltic Sea) wind patterns. To obtain an approximation of the wind at the $10 \mathrm{~m}$ level, used as the input to the wave model, the geostrophic wind speed was multiplied by 0.6 , and the direction was turned $15^{\circ}$ anticlockwise. The use of these data ignores the local vertical structure of air-flow, and thus possible trends in the air-sea temperature difference and associated variations and trends in the surface-level wind speed (Bumke \& Hasse 1989), and smooths out local variations in wind properties. However, because wave fields are formed through wind impact over large sea areas, it is likely that the outcome of simulations captures the core changes in the wave climate.

The regular rectangular grid (11545 sea points) extended from $09^{\circ} 36^{\prime} \mathrm{E}$ to $30^{\circ} 18^{\prime} \mathrm{E}$ and from $53^{\circ} 57^{\prime} \mathrm{N}$ to $65^{\circ} 51^{\prime} \mathrm{N}$. The wave-energy spectrum at each sea point was represented by 24 equally spaced directions. An extended range of 42 frequencies forming a geometric progression starting from $0.042 \mathrm{~Hz}$ with an increment (common ratio) of $1.1 \mathrm{up}$ to $\sim 2 \mathrm{~Hz}$ (wave periods from $23.9 \mathrm{~s}$ down to $0.5 \mathrm{~s}$ ) was used to ensure realistic wave growth rates in low wind conditions after calm situations that are frequent in this basin. See Räämet et al. (2010), Soomere \& Räämet $(2011,2014)$ and references therein for a detailed description of the model setup, its applicability for the Baltic Sea conditions and an analysis of the main properties of the wave climate and climatological changes in the reconstructed wave fields.

We used hourly time series of significant wave height, peak period and wave direction properties to calculate similar time series of the potential alongshore transport rate for each $\sim 6 \mathrm{~km}$ long coastal section matching the nearshore wave-model grid cell. This transport is evaluated using the Coastal Engineering Research Centre (CERC) approach (USACE 2002) for the entire sedimentary coast of the eastern Baltic Sea from Kaliningrad (Russia) to southern Estonia. The CERC method is based on the assumption that the potential alongshore transport rate is proportional to the beaching rate of the alongshore wave energy flux (wave power) per unit of length of the coastline, and thus accounts for the magnitude and direction of the wave energy flux. From the resulting time series of instantaneous potential transport for each coastal segment, we calculated the net transport (the residual sediment motion in some direction) and bulk transport (the total amount of sediment moved in any direction, back and forth alongshore) by waves over longer time intervals. See Soomere \& Viška (2014) for the particular implementation of the CERC model. 
The bulk transport, integrated over a $700 \mathrm{~km}$ stretch of the coastline from the Kaliningrad district to Pärnu in southern Estonia, steadily increases for 1970 to 2007 (Fig. 4), following increasing wind speed in the northern Baltic Proper for the same time interval (Broman et al. 2006, Soomere \& Räämet 2014). This increase $\left(\sim 0.7 \% \mathrm{yr}^{-1}\right.$ of the long-term mean) is statistically significant at a $95 \%$ level. The net transport has decadal variability almost matching that of the bulk transport. The increase in the net transport was much faster $\left(\sim 1.2 \% \mathrm{yr}^{-1}\right.$ of the longterm mean of the bulk transport) and also statistically significant at a $95 \%$ level. However, it breaks down at the end of the 1980s and is replaced by a decreasing trend of similar magnitude. The decrease was almost as rapid as the increase $\left(\sim 1 \% \mathrm{yr}^{-1}\right.$ of the longterm mean of the bulk transport) but statistically significant at a somewhat lower level of $89 \%$. This 'switch' obviously comes from a change in the wave direction - that change can only be possible if the wind direction had changed.

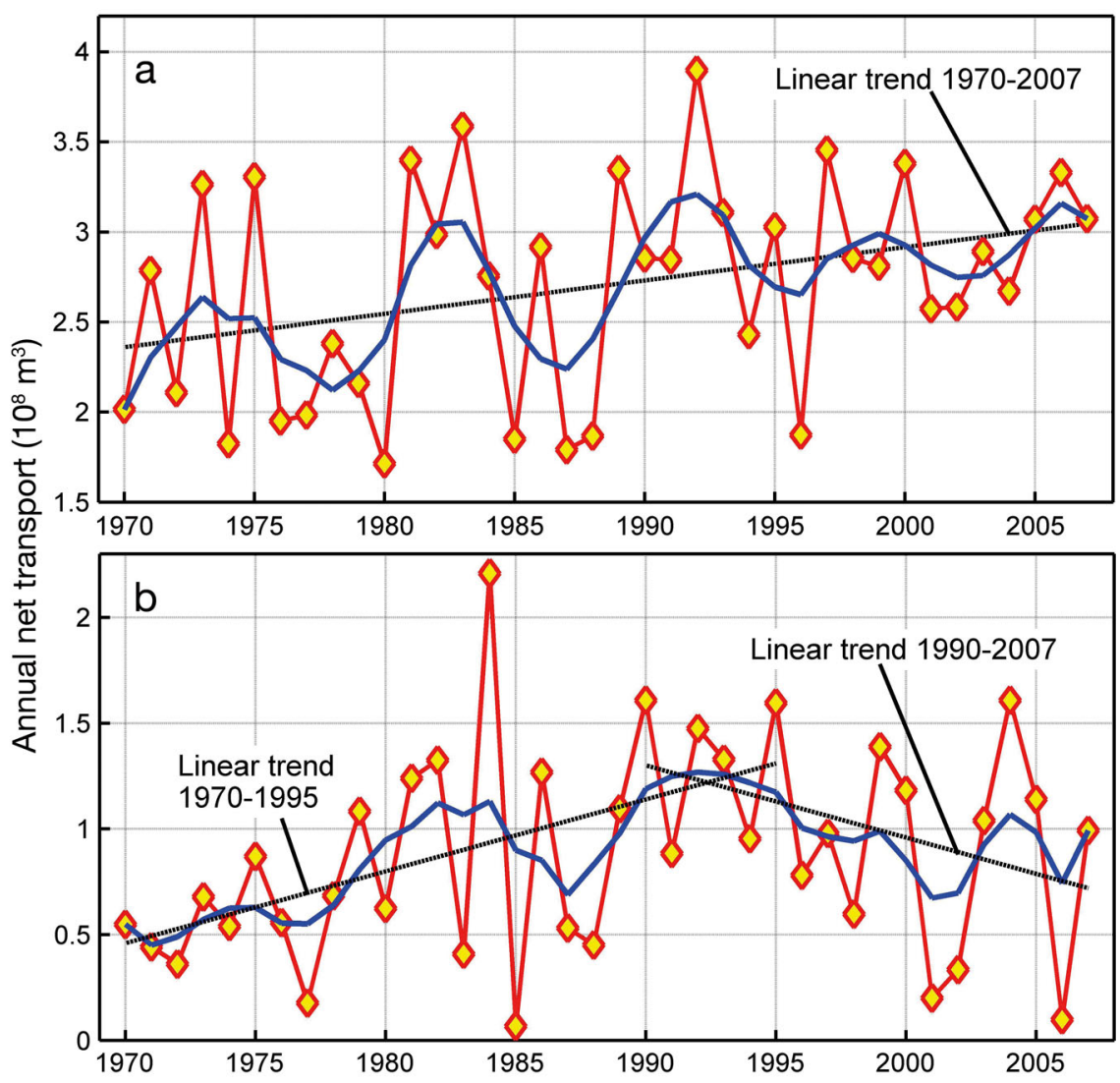

Fig. 4. (a) Bulk and (b) net average wave-driven potential sediment transport rate along the eastern coast of the Baltic Sea. Red: transport for individual years, blue: 5 yr moving average. The transport has been calculated using an implementation of the CERC model based on simulations of the Baltic Sea wave fields for 1970-2007 using the WAM model with a spatial resolution of 3 nautical miles and driven by adjusted geostrophic winds (Soomere \& Räämet 2011)

\section{ABRUPT TURN OF THE GEOSTROPHIC AIR-FLOW}

Owing to the complex shape of the Baltic Sea, changes to the wind direction may have a particularly strong impact on the wave height. Numerical simulations (Soomere \& Räämet 2011, 2014) indicated a major decrease (by $>15 \%$ ) in the annual mean wave height in the western part of the Baltic Proper between the islands of Öland and Gotland (Fig. 1) and to the south of these areas from 1970 to 2007. Because the wind speed has increased in this area during the simulation period (Broman et al. 2006, Soomere \& Räämet 2014), it is likely that changes to the wind direction are also behind this pattern of changes. The distribution of winds from different directions (the classical wind rose) does not reveal a change of sufficient magnitude (Lehmann et al. 2011). However, the air-flow direction (represented by a vector consisting of the average zonal and meridional wind components) reveals a substantial shift at 1987/88 (Fig. 5).

The annual average zonal component (averaged over areas of approximately $55 \times 55 \mathrm{~km}$ in the Baltic Proper and over somewhat smaller areas in the Gulf of Finland; Fig. 1) did not change, but the switch of the meridional component from close to zero to $\sim 1 \mathrm{~m} \mathrm{~s}^{-1}$ to the south is equivalent to a turn of the air-flow from its usual direction to the east to almost south-east (Soomere \& Räämet 2014).

The changes are localised both in time and space. They are concentrated in the southern Baltic Proper, and are not evident to the north of Saaremaa or to the west of Bornholm (Fig. 5). Most of the changes occurred in the windiest winter months (December, January, February [DJF]; Fig. 6). Almost no changes were evident during the spring (March, April, May [MAM]) and summer (June, July, August [JJA]) seasons. A certain increase in the average zonal wind component (from $\sim 2$ $\mathrm{m} \mathrm{s}^{-1}$ in 1970 to 1987 to the level of $3 \mathrm{~m}$ $\mathrm{s}^{-1}$ in 1988 to 2007) in winter (Fig. 6) was not statistically significant. This increase was not evident in the annual mean (Fig. 5) because of a similar decrease in the average over autumn months (September, October, November [SON]; Fig. 6). 

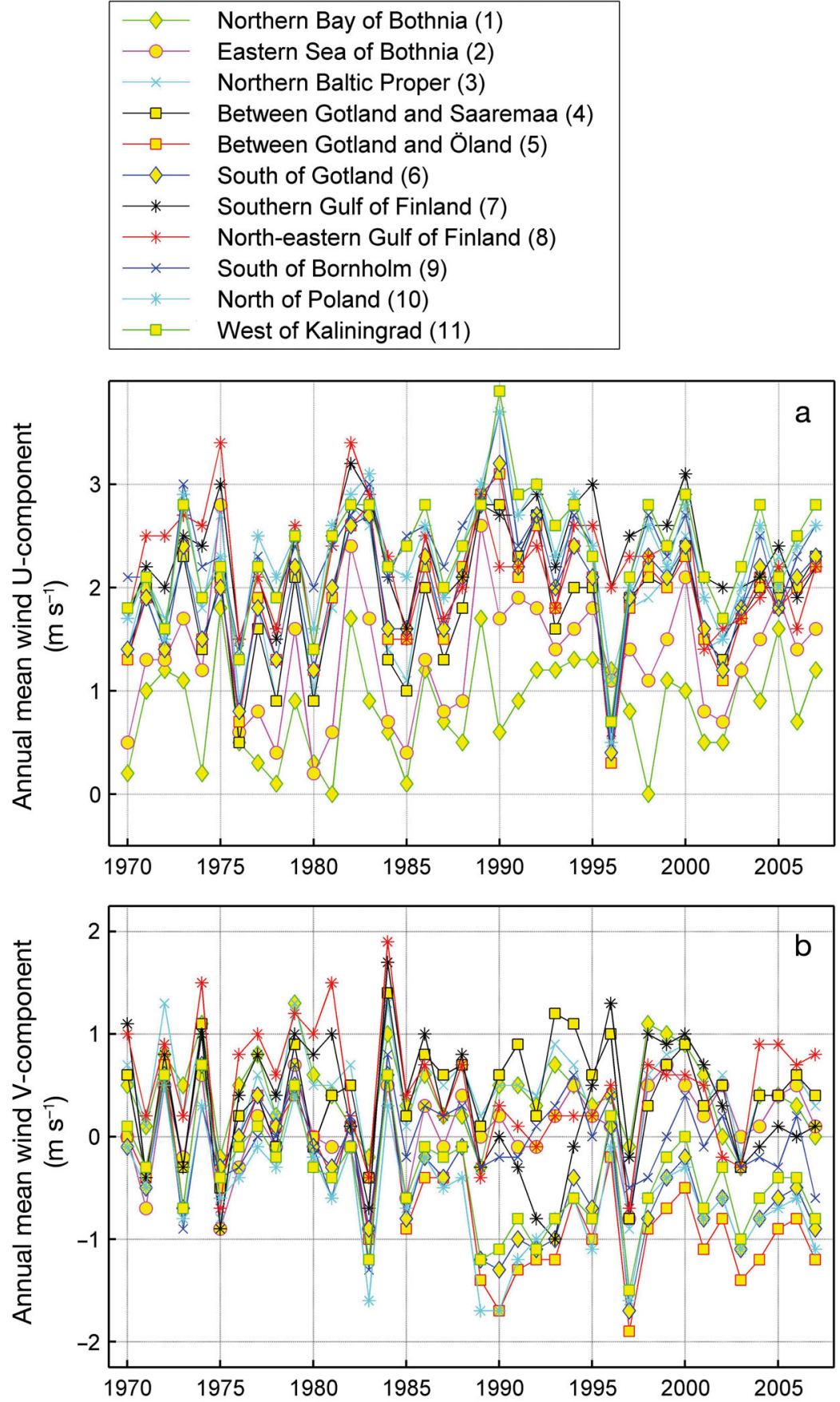

Fig. 5. Annual mean (a) zonal (U) and (b) meridional (V) component of air-flow of the adjusted geostrophic wind in different domains of the Baltic Sea indicated in Fig. 1. Significant changes to the meridional component occurred in 1987/88 in Areas 5, 6, 10 and 11 to the south of Gotland

change is statistically non-significant. Therefore, the annual mean geostrophic air-flow has substantially turned over the southern Baltic proper. The change is most pronounced in winter and possibly in early spring.

This turn in the air-flow direction is fully consistent with a shift of the area in the North Atlantic frequently hosting strong cyclones $(<980 \mathrm{hPa})$ from its position mostly to the west of Iceland in the 1960s and 1970s to a position far to the east of Iceland in the 1980s and the 1990s (Lehmann et al. 2011). Fig. 5 signals that this shift may have occurred abruptly, within at most a single year. Thus, it serves as a natural explanation of several other jump-like changes in the hydrography of the Baltic Sea (Mohrholz et al. 2006, Väli et al. 2013). As the key hydrophysical parameters (e.g. halocline depth; Väli et al. 2013) react to such changes with some delay, its sharpness may have remained unnoticed in many studies addressing the Baltic Sea (marine) climate (de Laat \& Crok 2013). Moreover, it is likely that this shift in air-flow and its implications only become clearly evident in a quite limited geographical area (Soomere \& Räämet 2014) and thus may be simply averaged out in studies of the entire Baltic Sea.

\section{DISCUSSION}

The described change in air-flow direction may have considerable impact on the entire Baltic Sea. The changes in the wave heights and approach directions have straightforward impact on the sediment transport patterns and areas of erosion and accumulation along sedimentary coasts of the Baltic Sea. Particularly strong impact is expected in regions

The average winter-time meridional wind component was close to zero in the southern Baltic proper from 1970 to 1987 and was $\sim 2 \mathrm{~m} \mathrm{~s}^{-1}$ to the south in 1988 to 2007. A certain change in this wind component may have occurred also in spring, but this where the approach angle of predominant waves becomes $>45^{\circ}$ and where the coastline may become unstable (Ashton et al. 2001), a feature that has been recently noted in the eastern Gulf of Finland (Ryabchuk et al. 2011). 


\section{a}
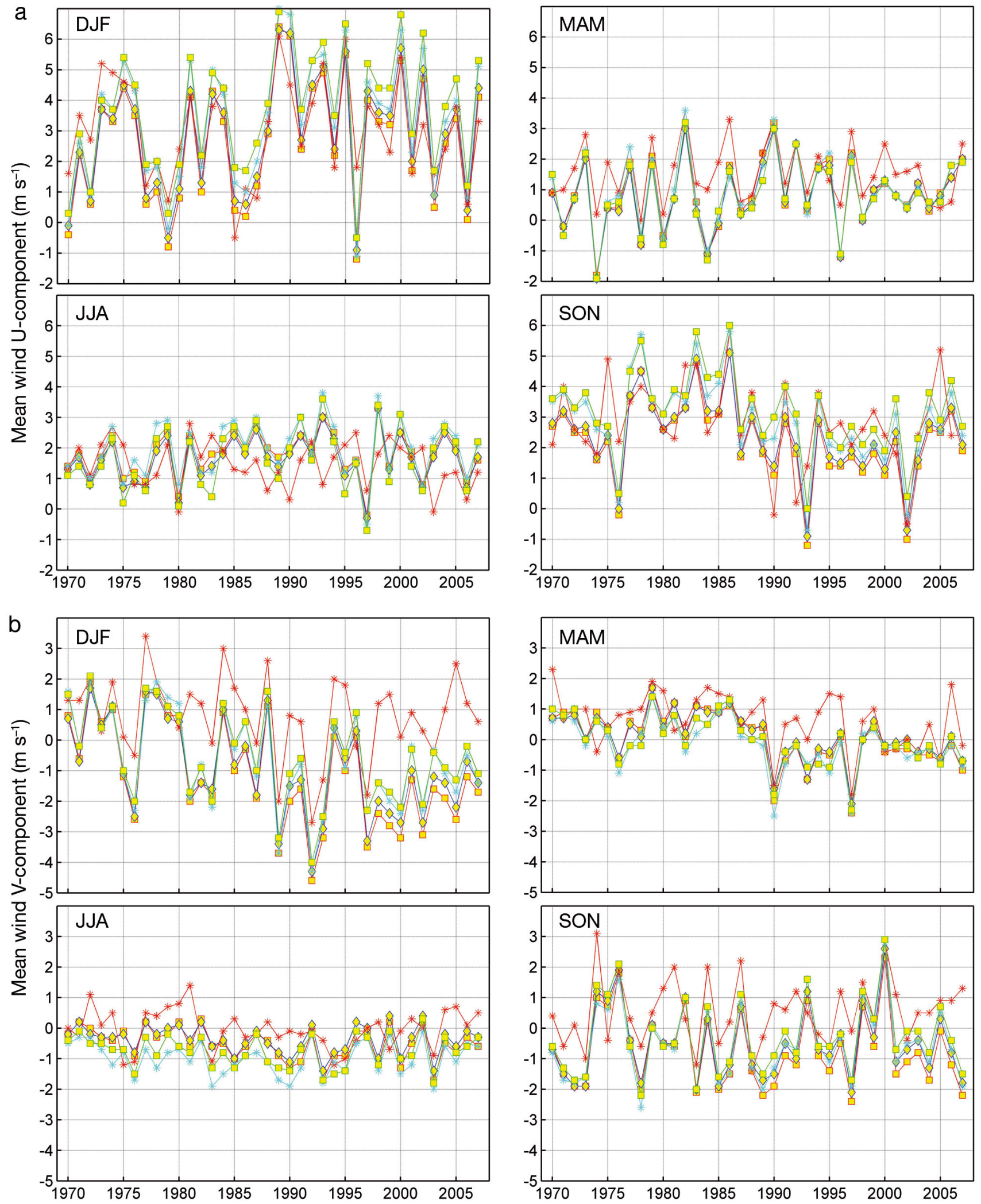

Fig. 6. Mean (a) zonal (U) and (b) meridional (V) component of air-flow of the adjusted geostrophic wind in different seasons (DJF: December, January, February; MAM: March, April, May; JJA: June, July, August; SON: September, October, November) in Areas 5, 6, 10 and 11 indicated in Fig. 1 (see key in Fig. 5). For comparison, the data for Area 8 located in the Gulf of Finland are also provided 
The possible implications of the described rotation of the air-flow over the southern Baltic Sea, probably the strongest ever identified signal of climate change in the area in the light of BACC (2008), are much wider. In short, the air-flow direction since 1988 is unfavourable for life in the deep sections of the Baltic Sea. Major Baltic inflows of salt water (MBIs) are multi-phase processes that can only occur through a specific sequence of air pressure patterns and wind events with a favourable direction (Schinke \& Matthäus 1998, BACC 2008). Therefore, they are highly sensitive to wind directions. Their frequency has radically decreased since the mid-1970s (Nausch et al. 2013), and only 3 MBIs have occurred since 1983. This decrease is usually explained by a combination of increased zonal circulation linked with intensified precipitation in the entire region and increased river runoff to the Baltic Sea (Schinke \& Matthäus 1998, BACC 2008). A probable mechanism that hampers MBIs may thus be an unfavourable pressure gradient (Zorita \& Laine 2000) that enhances zonal flow.

The demonstrated rotation of the air-flow direction has the potential to offer an alternative explanation of the cause of the changes in frequency and magnitude of the MBIs and associated phenomena. The described switch in the air-flow direction (which becomes clearly evident in certain wave properties and the course of wave-driven sediment transport) effectively does not influence the intensity of zonal circulation (Figs. $5 \& 6$ ). Instead, its presence means that the meridional component of the air-flow has significantly changed. This change, in essence, means a substantial increase in the long-lasting northwestern wind events at the expense of other wind episodes (e.g. western winds that are critical for an MBI to occur), and thus obviously impacts (generally diminishes) the frequency of occurrence of highly dynamical sequences that cause MBIs. The majority of changes are concentrated in the winter months, that is, in the middle of the relatively windy season during which most of the MBIs occur. Last but not least, this study suggests that proper analysis of climatological changes in wave properties and in the course of wave-driven coastal processes has great potential to reveal such shifts, which could also be important for other parts of the world.

Acknowledgements. Visual wave observations in 19462012 have been digitised from original diaries kindly provided by the Estonian, Latvian and Lithuanian hydrometeorological institutes. T.S. acknowledges support by the ESF grant 9125, Estonian target financing SF0140007s11 and IUT33-3, and European Regional Development Fund to
CENS and project TERIKVANT. S.R.B. acknowledges support from the RCUK Digital Economy grant EP/K039830/1 via the UK EPSRC research council. M.V. acknowledges support by the Mobilitas DoRa scheme for international PhD studies.

\section{LITERATURE CITED}

Alexandersson H, Tuomenvirta H, Schmith T, Iden K (2000) Trends of storms in NW Europe derived from an updated pressure data set. Clim Res 14:71-73

Ashton A, Murrey AB, Arnault O (2001) Formation of coastline features by large-scale instabilities induced by high-angle waves. Nature 414:296-300

BACC (The BACC Author Team) (2008) Assessment of climate change for the Baltic Sea Basin. Springer, Berlin

Backer H, Leppanen JM, Brusendorff AC, Forsius K and others (2010) HELCOM Baltic Sea Action Plan - a regional programme of measures for the marine environment based on the Ecosystem Approach. Mar Pollut Bull 60: 642-649

Bärring L, von Storch H (2004) Scandinavian storminess since about 1800. Geophys Res Lett 31:L20202, doi:10. 1029/2004GL020441

Bertin X, Prouteau E, Letetrel C (2013) A significant increase in wave height in the North Atlantic Ocean over the 20th century. Global Planet Change 106:77-83

Broman B, Hammarklint T, Rannat K, Soomere T, Valdmann A (2006) Trends and extremes of wave fields in the northeastern part of the Baltic Proper. Oceanologia 48(S): 165-184

Bumke K, Hasse L (1989) An analysis scheme for determination of true surface winds at sea from ship synoptic wind and pressure observations. Boundary-Layer Meteorol 47: 295-308

Conley DJ (2012) Ecology: save the Baltic Sea. Nature 486: 463-464

de Laat ATJ, Crok M (2013) A late 20th century European climate shift: fingerprint of regional brightening? Atmos Clim Sci 3:291-300

> Durack PJ, Wijffels SE, Matear RJ (2012) Ocean salinities reveal strong global water cycle intensification during 1950 to 2000. Science 336:455-458

> Elmgren R, Kumblad L, Rydin E, Wulff F (2012) Political backing to save the Baltic Sea. Nature 487:432

- Gulev SK, Grigorieva V (2004) Last century changes in ocean wind wave height from global visual wave data. Geophys Res Lett 31:L24302, doi:10.1029/2004GL021040

Gulev SK, Grigorieva V, Sterl A, Woolf D (2003) Assessment of the reliability of wave observations from voluntary observing ships: insights from the validation of a global wind wave climatology based on voluntary observing ship data. J Geophys Res C 108:C3236, doi:10.1029/2002 JC001437

> Hemer MA, Fan YL, Mori N, Semedo A, Wang XLL (2013a) Projected changes in wave climate from a multi-model ensemble. Nat Clim Change 3:471-476

Hemer MA, McInnes KL, Ranasinghe R (2013b) Projections of climate change-driven variations in the offshore wave climate off south eastern Australia. Int J Climatol 33: 1615-1632

Idier D, Castelle B, Poumadère M, Balouin Y and others (2013) Vulnerability of sandy coasts to climate variability. Clim Res 57:19-44 
Jaagus J, Kull A (2011) Changes in surface wind directions in Estonia during 1966-2008 and their relationships with large-scale atmospheric circulation. Estonian J Earth Sci 60:220-231

Lehmann A, Getzlaff K, Harlaß J (2011) Detailed assessment of climate variability in the Baltic Sea area for the period 1958 to 2009. Clim Res 46:185-196

Mohrholz V, Dutz J, Kraus G (2006) The impact of exceptionally warm summer inflow events on the environmental conditions in the Bornholm Basin. J Mar Syst 60: 285-301

Nausch G, Feistel R, Umlauf L, Mohrholz V, Siegel H (2013) Hydrographisch-hydrochemische Zustandseinschätzung der Ostsee 2012. Meereswiss Ber 91

Räämet A, Soomere T, Zaitseva-Pärnaste I (2010) Variations in extreme wave heights and wave directions in the northeastern Baltic Sea. Proc Estonian Acad Sci 59:182-192

Rosenhagen G, Tinz B (2013) New historical data of the southern Baltic Sea coasts. In: Reckermann M, Köppen S (eds) 7th Study Conference on BALTEX, 10-14 June 2013, Borgholm, Island of Öland, Sweden, International BALTEX Secretariat, Publication 53, p 84

Rosenthal Y, Linsley BK, Oppo DW (2013) Pacific Ocean heat content during the past 10,000 years. Science 342 : $617-621$

Ryabchuk D, Leont'yev I, Sergeev A, Nesterova E, Sukhacheva L, Zhamoida V (2011) The morphology of sand spits and the genesis of longshore sand waves on the coast of the eastern Gulf of Finland. Baltica 24:13-24

Schinke H, Matthäus W (1998) On the causes of major Baltic inflows - an analysis of long time series. Cont Shelf Res 18:67-97

Semedo A, Suselj K, Rutgersson A, Sterl A (2011) A global view on the wind sea and swell climate and variability from ERA-40. J Clim 24:1461-1479

Sepp M, Post P, Jaagus J (2005) Long-term changes in the frequency of cyclones and their trajectories in Central

Editorial responsibility: Eduardo Zorita,

Geesthacht, Germany and Northern Europe. Nord Hydrol 36:297-309

Soomere T (2013) Extending the observed Baltic Sea wave climate back to the 1940s. J Coast Res Special Issue 65: 1969-1974

Soomere T, Räämet A (2011) Spatial patterns of the wave climate in the Baltic Proper and the Gulf of Finland. Oceanologia 53:335-371

Soomere T, Räämet A (2014) Decadal changes in the Baltic Sea wave heights. J Mar Syst 129:86-95

Soomere T, Viška M (2014) Simulated sediment transport along the eastern coast of the Baltic Sea. J Mar Syst 129: 96-105

Soomere T, Weisse R, Behrens A (2012) Wave climate in the Arkona Basin, the Baltic Sea. Ocean Sci 8:287-300

Uggla Y (2007) Environmental protection and the freedom of the high seas: the Baltic Sea as a PSSA from a Swedish perspective. Mar Policy 31:251-257

USACE (2002) Coastal engineering manual. Department of the Army. U.S. Army Corps of Engineers, Manual No. 1110-2-1100

Väli G, Meier HEM, Elken J (2013) Simulated halocline variability in the Baltic Sea and its impact on hypoxia during 1961-2007. J Geophys Res C 118:6982-7000

Weisse R, von Storch H (2010) Marine climate and climate change. Storms, wind waves and storm surges. Springer, Berlin

> Wentz FJ, Ricciardulli L (2011) Comment on 'Global trends in wind speed and wave height.'. Science 334:905

Young IR, Zieger S, Babanin AV (2011) Global trends in wind speed and wave height. Science 332:451-455

Zaitseva-Pärnaste I (2013) Wave climate and its decadal changes in the Baltic Sea derived from visual observations. PhD thesis. Tallinn University of Technology, Tallinn

Zorita E, Laine A (2000) Dependence of salinity and oxygen concentrations in the Baltic Sea on large-scale atmospheric circulation. Clim Res 14:25-41

Submitted: May 5, 2014; Accepted: October 28, 2014

Proofs received from author(s): January 12, 2015 